\title{
Particle deposition in the trachea: in vivo and in hollow casts ${ }^{1}$
}

\author{
RICHARD B. SCHLESINGER and MORTON LIPPMANN
}

\begin{abstract}
Institute of Environmental Medicine, New York University Medical Center, 550 First Avenue, New York, NY 10016 and Department of Biology, Graduate School of Arts and Science, New York University, Washington Square, New York, NY 10016
\end{abstract}

\begin{abstract}
Schlesinger, R. B. and Lippmann, M. (1976). Thorax, 31, 678-684. Particle deposition in the trachea : in vivo and in hollow casts. The pattern of deposition within the respiratory tract of potentially harmful particulates is a major factor in assessing any risk from individual and community exposures. Although the trachea is the most easily observed of the conductive airways, very little information concerning its particle collection characteristics is available, information which is essential for a complete and realistic description of particle deposition patterns within the entire respiratory tract. Data on tracheal deposition are also needed for development of accurate predictive models for particle deposition. The pattern of particle deposition in the trachea, and its relation to air flow, was studied in a hollow cast of the human larynx-tracheobronchial tree. Results were compared with data obtained in humans in vivo and from previous studies in hollow casts. In addition, the relevance of tracheal deposition in the hollow cast test system to deposition in vivo was examined by a direct comparison of deposition in a cast prepared from the lungs of donkeys previously studied in a series of in vivo tests. The disturbance of the air flow within the trachea caused by the larynx promoted the deposition of suspended particulates throughout the length of the trachea, and especially in proximal regions. This proximal deposition was due both to direct impaction from the air jet coming from the glottis and to effects of the turbulent flow. Turbulence produced inhomogenous deposition patterns within the trachea for particles of all sizes, although its effect was more pronounced as size decreased. Tracheal deposition in the human cast was within the range of normal in vivo tracheal deposition only when a larynx was used during cast test exposures; this emphasizes the need for the use of realistic experimental test systems for the study of particle deposition patterns. The relative patterns of deposition in casts of the donkey trachea and in the same tracheas in vivo were similar
\end{abstract}

\section{INTRODUCTION AND BACKGROUND}

The pattern of deposition of inhaled particulates is an important determinant of the risk from environmentally induced disease or injury. The trachea is the first conductive airway which particles encounter after passing through the upper respiratory tract, and it is also the most readily accessible of all the conductive airways. Although data are available on tracheal air flow patterns (Proetz, 1951; West and Hugh-Jones, 1959; Dekker, 1961; Owen, 1969; Sekihara, Olsen, and Filley, 1969; Olson et al., 1973) and mucociliary transport rates (Kensler and Battista, 1966; Morrow, Gibb and Gazioglu, 1967; Albert et al., 1974; Santa Cruz et al., 1974; Yeates et al., 1975), there has been very little in-

1 These studies were supported by Grant No. ES-00881 and are part of a centre programme supported by Grant No. ES-00260, both from the National Institute of Environmental Health Sciences vestigation of the intratracheal pattern of particle deposition. A complete and realistic understanding of deposition within the respiratory tract is nof possible without data on tracheal deposition pat $>$ terns obtained in realistic experimental systems.

This paper describes tracheal particle deposition patterns and provides information on the relation between deposition and air flow pattern, based upon the study of deposition in a hollow cast of the human larynx-tracheobronchial tree. Results were compared with data from previous studies using casts, and with work performed in humans in vivo In addition, the relevance of tracheal deposition as measured in a cast to that actually occurring $i$ \% vivo was also studied by examining deposition in donkeys in vivo and in casts prepared from the same donkeys' lungs. 
One of the major factors affecting the tracheal deposition pattern is the flow field resulting from entry of the inspired air through the larynx as a jet, directed towards the posterior tracheal wall. This results in the production of turbulence at relatively low flow rates. Using hollow casts of the human trachea which extended through the first bifurcation, coupled with a larynx having the glottis in a 'natural respiratory position', Dekker (1961) found that the flow through the trachea changed from laminar to turbulent at a mean value of 5.8 litres/min. Olson et al. (1973), using a cast extending through the segmental bronchi and various larynxes moulded to be representative of their shape at different steady inspiratory flow rates, found that unstable flow began in the trachea for rates of $\sim 9$ litres/min. Thus, since our cast deposition tests were performed using a larynx, and at flow rates $\geq 15$ litres/min, some degree of turbulence was produced within the trachea during all test runs. Any turbulence generated is probably contained outside a laminar boundary layer, which would exist along the tracheal wall (Pedley, Schroter, and Sudlow, 1971; Bell, 1974).

The deposition of particles within the trachea increases with turbulence. Turbulent eddies inject submicron particles into the laminar boundary layer, from which they may deposit by Brownian diffusion (Owen, 1969). Eddies may also enhance the inertial deposition of larger particles by projecting them towards the tracheal wall at a higher local rate than would occur in the absence of any secondary flow (Davies, 1966).

\section{METHODS OF PROCEDURE}

DEPOSITION WITHIN THE TRACHEA OF A HUMAN AIRWAY CAST Details of the preparation of the hollow tracheobronchial tree cast, test exposure technique, aerosol generation, and detection system for analysis of deposited activity are given elsewhere (Schlesinger, Cohen, and Lippmann, 1974). The technique involved exposure of a hollow, silicone rubber cast, which extended to bronchi of $\sim 0.2 \mathrm{~cm}$ diameter, to radioactively tagged $\left({ }^{99 \mathrm{~m}} \mathrm{Tc}, \mathrm{T}_{\frac{1}{2}}=6 \mathrm{hr}\right.$ ) ferric oxide microspheres at constant 'inspiratory' flow rates of either 15,30 or 60 litres/min while suspended within a Plexiglas ${ }^{\circledR}$ 'artificial thorax'. Mass median aerodynamic diameters ${ }^{1}$ (MMAD) ranged from 0.26 to 8.0 $\mu \mathrm{m}$. The cast was coated with a thin layer of silicone oil (viscosity $=50 \mathrm{cP}$ ) before each test run; the oil acted to simulate the wet surface of the actual tracheo-

\footnotetext{
1 Aerodynamic diameter is the diameter of a spherical particle of unit density having the same settling velocity as the particle in question; it is a useful parameter for characterizing particle behaviour in air, and takes into account actual size, density, and aerodynamic drag. At the mass median diameter, $50 \%$ of the aerosol is in particles with greater diameters, and $50 \%$ is in particles with smaller diameters
}

bronchial tree. Deposition within $1 \mathrm{~cm}$ regions along the trachea was measured with a multiple convergent channel (focusing) collimator, and a $7.6 \mathrm{~cm}$ ( 3 inch) diameter $\mathrm{NaI}$ ( $\mathrm{Tl}$-activated) scintillation detector.

A hollow larynx cast was used during each test exposure in order to produce more realistic entry conditions into the trachea. Because the geometry of the laryngeal airway changes with flow rate, three larynxes were modeled from a cadaveric larynx, each representative of one of the flow rates used. Details of the preparation of these casts have been given elsewhere (Schlesinger et al., 1974).

DEPOSITION WITHIN THE DONKEY TRACHEA The donkey has been used as an experimental animal for a number of particle clearance studies in this laboratory (Albert et al., 1968; 1969; 1974; Berger, 1974). For the current study, each of two donkeys inhaled radioactively tagged $\left({ }^{9} \mathrm{~m} \mathrm{Tc}\right)$ ferric oxide aerosols through two vinyl catheters inserted into the nostrils. A plastic bag was placed around the catheters to seal the nose and mouth. Each donkey was exposed to test aerosol, generated by the same system used for the human cast tests, for 5 minutes. Four tests, using aerosols ranging in size from $\sim 0.3 \mu \mathrm{m}$ to $\sim 5 \mu \mathrm{m}$ (MMAD), were performed with each animal.

The donkey breathing pattern during exposure was monitored using a constant temperature anemometer (Thermo-Systems Model 1034) coupled to an electronic chart recording module. The measurement of initial tracheal deposition was made within one minute after the end of each exposure period using a rectilinear scanner, which viewed $7.6 \mathrm{~cm}$ wide segments from the base of the neck to below the larynx (Albert et al., 1974). These segments were designated as positions 6 to 3 respectively.

Following the in vivo exposure series, the donkeys were sacrificed and the lungs and larynx were removed. The trachea and one lung of each donkey were cast, using the same procedure as for the human cast. The donkey larynx was cast with its geometry representative of quiet respiration (Sisson, 1953). The trachea of each cast was marked off into $7.6 \mathrm{~cm}$ counting regions, which corresponded to those studied in the in vivo tests.

Four tests, corresponding to the four in vivo tests, were performed using each cast. For each test, the larynx-tracheobronchial tree was suspended within a Plexiglas ${ }^{\circledR}$ 'artificial thorax', in a manner believed to be close to the way the tracheobronchial tree was situated in vivo, although there was no way to determine whether the correspondence was exact. The ferric oxide aerosols had similar MMADs to those used for the in vivo tests and were tagged and generated in the same manner. A constant 'inspiratory' type 
flow, which corresponded to the average inspiratory flow rate of the comparable in vivo test, was drawn through the cast during each exposure. The tracheal deposition pattern was determined by use of the rectilinear scanner to view comparable tracheal regions as were viewed in vivo.

\section{RESULTS AND DISCUSSION}

HUMAN TRACHEAL MORPHOMETRY Available data on human tracheal dimensions are presented in Table I and compared with tracheal morphometry of the human airway cast. Since the cast was prepared from the lungs of a male, only data for males are presented. The length and diameter of the cast trachea are seen to fall within reported ranges.

T A B L E I

TRACHEAL MORPHOMETRY

\begin{tabular}{|c|c|c|}
\hline Author and Technique & $\begin{array}{l}\text { Mean Length } \\
\text { (cm) }\end{array}$ & $\underset{(\mathrm{cm})}{\text { Mean Diameter }}$ \\
\hline Present study & $10 \cdot 60$ & $1 \cdot 75$ \\
\hline $\begin{array}{l}\text { Brückner (1952) Stereo- } \\
\text { radiographs obtained in } \\
\text { inspiration with expanded } \\
\text { chest in } 23 \text { men }\end{array}$ & - & $(\mathrm{r}=1 \cdot 5-2 \cdot 0)^{1}$ \\
\hline $\begin{array}{l}\text { Merendino and Kiriluk (1954) } \\
\text { Measurements on 55 } \\
\text { cadavers, both sexes }\end{array}$ & - & 1.90 \\
\hline $\begin{array}{l}\text { Jesseph and Merendino (1957) } \\
\text { Measurements on } 21 \text { male } \\
\text { cadavers }\end{array}$ & - & $\underset{(r=1 \cdot 5-2 \cdot 7)}{2 \cdot 2 \pm 0 \cdot 26^{2}}$ \\
\hline $\begin{array}{l}\text { Schlesinger and Lippmann } \\
\text { (1972) Measurements on } \\
\text { three casts }\end{array}$ & $10 \cdot 16 \pm 0 \cdot 84$ & $1.91 \pm 0.26$ \\
\hline $\begin{array}{l}\text { Phalen et al. (1975) } \\
\text { Measurements on one cast }\end{array}$ & $11 \cdot 0$ & $1 \cdot 7$ \\
\hline
\end{tabular}

INTRATRACHEAL DEPOSITION PATTERN IN THE HUMAN AIRWAY CAST Figures 1 a-c show the deposition pattern within the cast trachea for all test runs.

A deposition peak for particles $\geq 1 \cdot 2 \mu \mathrm{m}$ was observed, generally within the first $2 \mathrm{~cm}$ downstream from the larynx. This peak is due, at least partly, to the direct impaction of particles from the incoming air jet.

In previous studies (Schlesinger and Lippmann, 1972; Schlesinger, 1975) hollow casts which extended through the segmental bronchi were exposed without a larynx to ferric oxide aerosols. Deposition profiles for a number of test runs using these casts are shown in Figure 2. Tracheal deposition is more uniform in these earlier runs, as compared with those obtained in the current study. The enhanced proximal deposition seen in Fig. 2 for $6.3 \mu \mathrm{m}$ particles at 55 litres $/ \mathrm{min}$ may be due to the more highly turbulent nature of the flow $\bar{c}$ (Sekihara et al., 1969).

The nonuniformity of the deposition pattern for $\Omega$ the $\sim 0.3 \mu \mathrm{m}$ particles is an indicator of the degree of $\%$ departure from ideal laminar flow within the trachea; $\vec{O}$ in laminar flow, these particles would deposit by Brownian diffusion uniformly along the tracheal wall $\vec{\sigma}$ (Martin and Jacobi, 1972). As flow rate increases, the inhomogeneity would increase with an increase in $\times$ turbulence. As expected, the most uniform deposition $\stackrel{\omega}{-}$ pattern for these particles occurred at a flow rate of 15.9 litres/min (Fig. 1a). At 30 litres/min (Fig. 1b) and at 60 litres/min (Fig. 1c) there was a progressive de- ${ }^{\infty}$ parture from deposition uniformity.

In runs at 30 and 60 litres $/ \mathrm{min}$ with the $\sim 0.3 \mu \mathrm{m} \vec{\sigma}$ particles, a deposition peak was observed within the $\mathbb{}$ first $2 \mathrm{~cm}$ distal to the larynx. Since deposition due to $\Phi$ inertial impaction is negligible for these particles, this peak indicates the presence of turbulence in this $\stackrel{\mathbb{D}}{-}$ region. Turbulence in the upper trachea may also $\overrightarrow{0}$ cause a proximal shift in the deposition of larger $/ \vec{~}$ particles, resulting in enhanced deposition over that due solely to direct jet impaction.

An enhancement of proximal tracheal deposition due to turbulence was observed by Proetz (1951), who studied inspiratory currents and chemical powder $\frac{\circ}{\square}$ deposition in a cast extending from the mouth to $1 \stackrel{\varrho}{~}$ inch $(2.5 \mathrm{~cm})$ below the larynx. He noted that areas of $\overline{\vec{O}}$ turbulence corresponded with deposits of powder, and both occurred on the rear wall of the trachea below the larynx.

Another example of the relation between flow struc- $-\overrightarrow{\overrightarrow{0}}$ ture within the trachea and ultimate deposition pattern may be taken from Fig. 1c. For runs at $60^{\times}$ litres/min, the region which extended from 8 to $9 \mathrm{~cm} 3$ distal to the larynx exhibited enhanced deposition. Based upon measurements performed using a hollow cast, including a larynx, Olson et al. (1973) developed velocity contour maps for various positions within? the trachea. At 60 litres/min, the highest velocity contours were found to be extremely close to the dorsal wall in the lower part of the trachea. Those $N$ contours which exhibit the greatest velocity should also contain the greatest concentration of particles. N In a relatively highly turbulent flow regime, such as $\omega$ that at 60 litres/min, particles very close to the walle may acquire considerable velocities, causing them to be deposited by inertia (Fuchs, 1964), resulting in areas with concentrated deposits.

As inspiratory flow rate changes, the geometry of the larynx changes, resulting in alterations in the structure of the turbulence within the trachea (Olson $\frac{\text { ? }}{\mathbb{D}}$ et al., 1973). Any changes in the distribution and음 
(a)

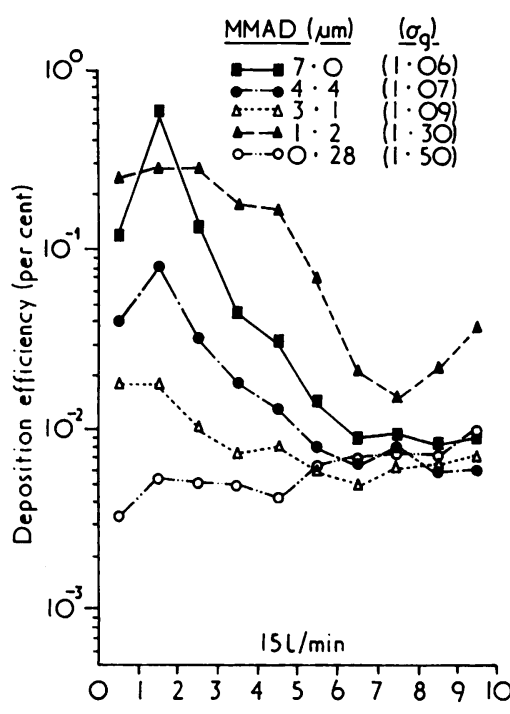

(b)

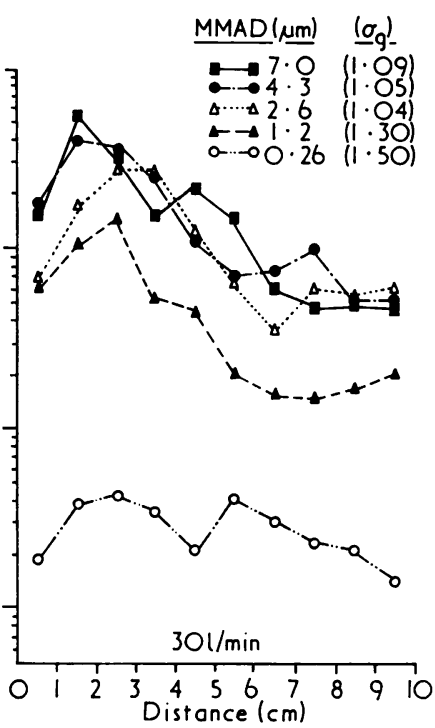

(c)

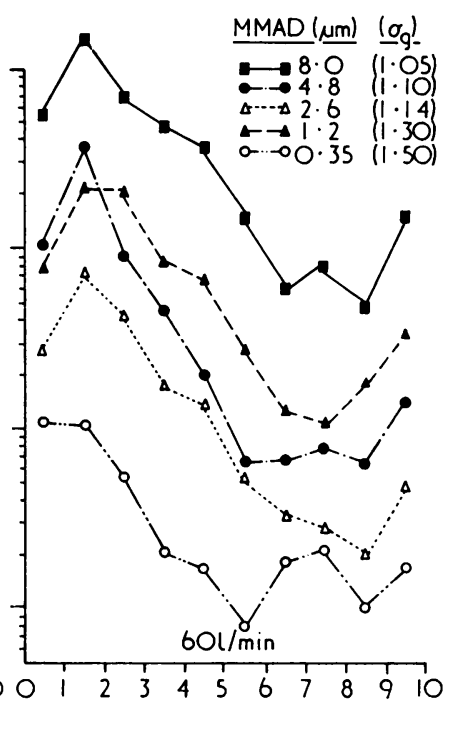

FIG. $1(a-c)$. Intratracheal deposition patterns at three flow rates. Each point is plotted at the midpoint of a $1 \mathrm{~cm}$ length along the trachea and represents the measured deposition efficiency within this length. Efficiency is the percentage of aerosol entering each $1 \mathrm{~cm}$ region which deposits within it. Distance is measured from the distal end of the cricoid cartilage: $M M A D=$ mass median aerodynamic diameter; $\sigma_{g}=$ geometric standard deviation.

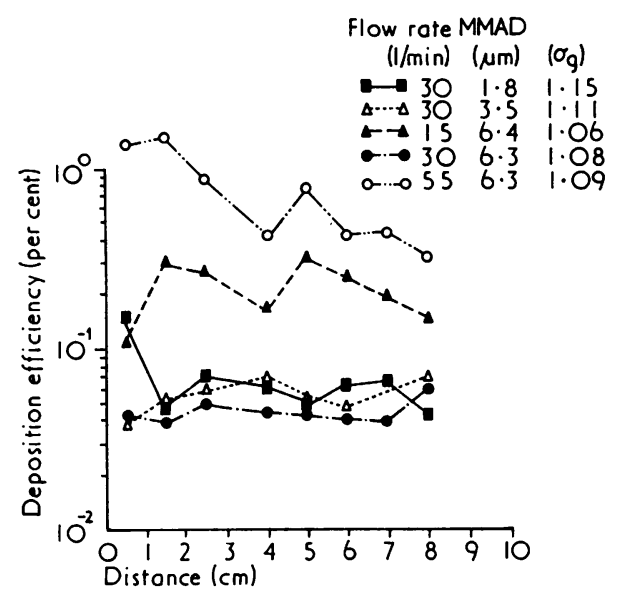

FIG. 2. Intratracheal deposition patterns in a cast exposed to aerosol without a larynx. Each point is plotted at the midpoint of a $1 \mathrm{~cm}$ length along the trachea and represents the measured deposition efficiency within this length. Efficiency is the percentage of aerosol entering each $1 \mathrm{~cm}$ region which deposits within it. Distance is measured from the distal end of the cricoid cartilage: $M M A D=$ mass median aerodynamic diameter; $\sigma_{g}=$ geometric standard deviation. strength of the secondary flows would affect the pattern of intratracheal deposition; this is evident in Fig. 1 for the deposition of similarly sized particles at different flow rates. However, the deposition of the $1.2 \mu \mathrm{m}$ particles was affected more by changes in air flow patterns obtained by increasing the flow rate than was the deposition of the larger particles, whose motion was increasingly determined by inertial forces.

TRACHEAL DEPOSITION IN HUMANS in vivo Figure 3 shows the tracheal deposition of ferric oxide aerosols obtained during in vivo human test exposures (Lippmann, Albert, and Peterson, 1971; Lippmann, unpublished data). These data are compared with that obtained for tracheal deposition within various hollow casts. Deposition is plotted versus the inertial parameter $d_{a}^{2} Q_{a}$, where $d_{a}=$ mass median aerodynamic particle diameter in $\mu \mathrm{m}$, and $\mathrm{Q}_{\mathrm{a}}=$ average inspiratory flow rate in litres/min. This dimensional parameter permits data collected in tests with various average flow rates and particle sizes to be normalized (Lippmann and Albert, 1969). The scatter seen in the in vivo data is due largely to variability in the flow pattern through the glottis between individuals and, possibly, even in one individual as the position of the 


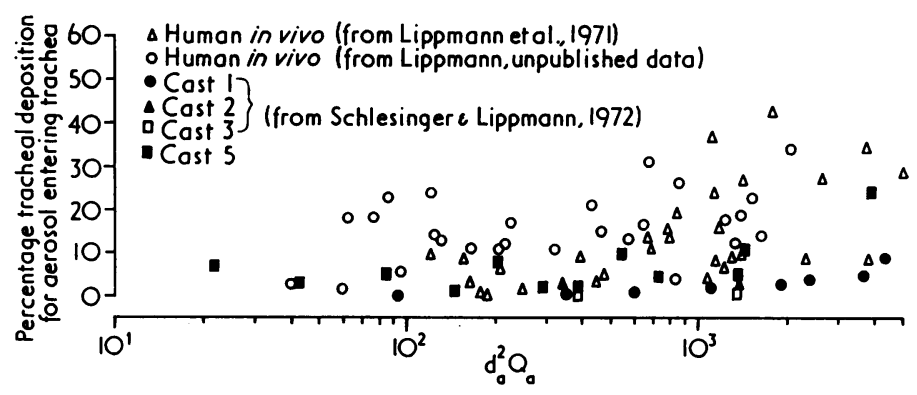

FIG. 3. Comparison of tracheal deposition in humans in vivo and in casts exposed with a larynx (cast 5) and without a larynx (casts 1, 2, and 3). The area designated as trachea in vivo includes the tracheal-main bronchial bifurcation and short proximal segments of the main bronchi; values for tracheal deposition in the casts have been adjusted to include the additional regions.

vocal cords changes during inspiration (Dekker, 1961).

The tracheal deposition percentages obtained with the human airway cast used in the current study (cast 5) generally fall within the range defined by the values for in vivio deposition. Casts 1 , 2 , and 3 were from a previous study (Schlesinger and Lippman, 1972) and had been exposed to test aerosols without an upstream larynx. Overall tracheal deposition within these casts was less than that observed in vivo.

INTRATRACHEAL DEPOSITION PATTERNS IN DONKEY TRACHEA: CORRESPONDENCE OF DEPOSITION in vivio AND IN CASTS A number of inherent sources of error and variability must be considered when directly comparing deposition in casts and in in vivo systems. For the cast system, variability in repeated tests with the same cast under the same exposure conditions is due to radioactivity counting statistics, ie, temporal fluctuations in $\gamma$-ray flux. The magnitude of this variability can be calculated. For in vivo tests performed on the same animal under identical exposure conditions, the fraction of total tracheal deposition occurring in each counting position may differ due to: (1) counting statistics, as above; (2) slight variations in positioning of the donkey relative to the detectors during each test; and (3) variability due to physiological factors.

The variability attributable to the latter two factors can be determined directly for each animal on the basis of a series of repetitive tests. However, the animals used in the current tests were selected because they had physical disabilities, unrelated to their lungs, which limited their further use. One $\mathbb{\Phi}$ was increasingly lame, and the other had failing $\overrightarrow{0}$ eyesight. Accordingly, only one in vivo test at each particle size could be performed in each of them. However, data on variability were available for a substantial number of repetitive tests which had been performed on three other donkeys maintained in the same colony, and these data were used as the basis for determination of an in vivo variability $\varrho$ factor.

Each of these three donkeys had had 33-40 de- 3 position tests performed with particle sizes of $\sim 5 \mu \mathrm{m}$ (MMAD), ie, the largest size used in the current study. The variability factors for each tracheal position were expressed as the mean 윽 coefficient of variation of the fraction of the total $\underset{x}{ }$ tracheal deposition with occurred within each of $\frac{0}{3}$ the tracheal positions for all test runs. Since variability did not significantly differ $(P<0.01)$ with position along the trachea, the in vivo variability factor was taken to be the mean coefficient of $\mathrm{O}$ variation for all tracheal positions for all tests, ie, $\frac{D}{O}$ $15.0 \%$. This value was the same $(P<0.01)$ for tests at other particle sizes in these animals, and also the $N$ same $(\mathrm{P}<0.01)$ for six tests with $5 \mu \mathrm{m}$ particles previously performed on Cleo and Anthony. Thus the fractional tracheal deposition in all donkeys $\omega$ appears to have similar variability.

Each value for fractional tracheal deposition ine the cast may be compared to the actual measured $\mathbb{D}$ in vivo value, taking into account the estimated. range of normal variability from the available in vivo data.

To perform the in vivo-cast comparison, the measured deposition in each of the donkey tracheal 
positions was expressed as a fraction of the total activity deposited within the tracheal in that particular test. The fractional deposition within each position for each cast test was then divided by the fractional deposition within the comparable position for the corresponding in vivo test. A ratio of 1.0 indicates that the in vivo and cast fractional deposition values were identical. In Fig. 4, the calculated ratios are shown, together with 'error' bars whose magnitude was based upon the error and variability analysis discussed above. Twentyfive out of 28 ratios overlap the value of $1 \cdot 0$, indicating that, in general, the tracheal deposition patterns in the cast and in vivo are not different. No ratios are shown for donkey Anthony using $\sim 0.3 \mu \mathrm{m}$ particles, because there was no measurable deposition in his trachea in either the in vivo or cast tests.

(a)
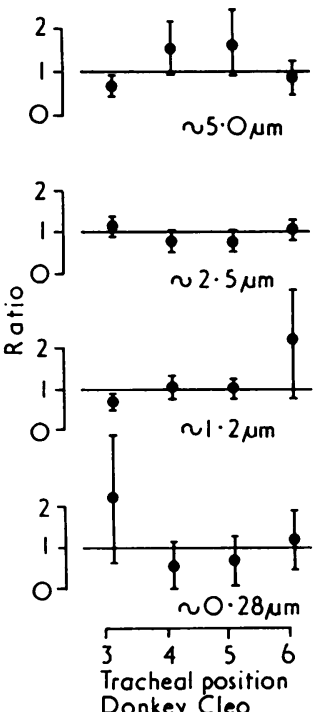

FIG. 4. $(a-b)$ Comparison of donkey tracheal deposition in vivo and in casts. The MMADs for the comparable in vivo-cast tests are indicated. The method of determining the ratio is described in the text. The lines through each point are based on a variability factor, as described in the text.

The influence of the larynx on tracheal deposition is evident from data in Table II. For particles larger than $1 \mu \mathrm{m}$, position 3 , which is immediately distal to the larynx, had the greatest deposition of any tracheal region. In the in vivo and cast tests on Cleo, using $\sim 0.3 \mu \mathrm{m}$ aerosols, the absolute amount of deposition was very low in all positions but was highest in position 6 .
T A B L E I I

DEPOSITION PATTERN IN THE DONKEY TRACHEA: IN CASTS AND IN VIVO

\begin{tabular}{|c|c|c|c|c|c|}
\hline \multirow[b]{2}{*}{ Donkey } & \multicolumn{2}{|c|}{$\begin{array}{l}\text { Particle Size }(\mu \mathrm{m}) \\
\text { MMAD }\end{array}$} & \multirow{2}{*}{$\begin{array}{l}\text { Tracheal } \\
\text { Position }\end{array}$} & \multicolumn{2}{|c|}{$\begin{array}{c}\text { Relative } \\
\text { Deposition }\end{array}$} \\
\hline & Cast & In Vivo & & Cast & In Vivo \\
\hline \multirow[t]{4}{*}{ Anthony } & $5 \cdot 1(1.08)^{2}$ & $5.3(1.04)$ & $\begin{array}{l}3 \\
4 \\
5 \\
6\end{array}$ & $\begin{array}{l}2.1 \\
1.9 \\
1.7 \\
1.0\end{array}$ & $\begin{array}{l}1.5 \\
1.2 \\
1.1 \\
1.0\end{array}$ \\
\hline & $2 \cdot 5 \quad(1.07)$ & $2.4(1.03)$ & $\begin{array}{l}3 \\
4 \\
5 \\
6\end{array}$ & $\begin{array}{l}2.4 \\
1.3 \\
1.0 \\
1.5\end{array}$ & $\begin{array}{l}1.9 \\
1.0 \\
1.5 \\
1.8\end{array}$ \\
\hline & $1 \cdot 2(1 \cdot 30)$ & $1.2(1.30)$ & $\begin{array}{l}3 \\
4 \\
5 \\
6\end{array}$ & $\begin{array}{l}1.4 \\
1.0 \\
1.3 \\
1.7\end{array}$ & $\begin{array}{l}1.7 \\
1.0 \\
1.5 \\
1.4\end{array}$ \\
\hline & $0.28(1.50)$ & $0.28(1.50)$ & $3-6$ & $* * *$ & $* * *$ \\
\hline \multirow[t]{4}{*}{ Cleo } & $5 \cdot 1 \quad(1.08)$ & $9.4(1.08)$ & $\begin{array}{l}3 \\
4 \\
5 \\
6\end{array}$ & $\begin{array}{l}1.6 \\
1.5 \\
1.1 \\
1.0\end{array}$ & $\begin{array}{l}3.8 \\
1.6 \\
1.0 \\
1.7\end{array}$ \\
\hline & $2.5(1.07)$ & $2.9(1 \cdot 11)$ & $\begin{array}{l}3 \\
4 \\
5 \\
6\end{array}$ & $\begin{array}{l}6.6 \\
1.5 \\
1.0 \\
1.9\end{array}$ & $\begin{array}{l}4.6 \\
1.5 \\
1.0 \\
1.5\end{array}$ \\
\hline & $1 \cdot 2(1 \cdot 30)$ & $1 \cdot 2(1 \cdot 30)$ & $\begin{array}{l}3 \\
4 \\
5 \\
6\end{array}$ & $\begin{array}{l}1.8 \\
1.1 \\
1.4 \\
1.0\end{array}$ & $\begin{array}{l}5 \cdot 5 \\
2 \cdot 3 \\
3 \cdot 0 \\
1 \cdot 0\end{array}$ \\
\hline & $0 \cdot 28(1 \cdot 50)$ & $0.28(1.50)$ & $\begin{array}{l}3 \\
4 \\
5 \\
6\end{array}$ & $\begin{array}{l}2.1 \\
1.0 \\
1.6 \\
3.3\end{array}$ & $\begin{array}{l}1.0 \\
1.9 \\
2.5 \\
2.9\end{array}$ \\
\hline
\end{tabular}

${ }^{1}$ All positions were normalized with 1.0 for the position with the leas deposition for each test.

2 Geometric standard deviation.

***No measurable deposition.

\section{REFERENCES}

Albert, R. E., Berger, J., Sanborn, K., and Lippmann, M. (1974). Effects of cigarette smoke components on bronchial clearance in the donkey. Archives of Environmental Health, 29, 96.

, Spiegelman, J. R., Lippmann, M., and Bennett, R. (1968). The characteristics of bronchial clearance in the miniature donkey. Archives of Environmental Health, 17, 50.

, Shatsky, S., and Lippmann, M. (1969). The effect of acute exposure to cigarette smoke on bronchial clearance in the miniature donkey. Archives of Environmental Health, 18, 30.

Bell, K. A. (1974). Aerosol deposition in models of a human lung bifurcation. Ph.D. Thesis, California Institute of Technology.

Berger, J. (1974). Toxic and physiologic factors affecting mucociliary clearance and particle deposition in the lungs of donkeys. Ph.D. Thesis, New York University.

Brückner, H. (1952). Die Anatomie der Lufttröhre beim lebenden Menschen. Zeitschrift für Anatomie und Entwicklungsgeschichte, 116, 276.

Davies, C. N. (1966). Deposition from moving aerosols. 
In Aerosol Science, edited by C. N. Davies, p. 408. Academic Press, New York.

Dekker, E. (1961). Transition between laminar and turbulent flow in human trachea. Journal of Applied Physiology, 16, 1060.

Fuchs, N. A. (1964). The Mechanics of Aerosols. Pergamon Press, New York.

Jesseph, J. E. and Merendino, K. A. (1957). The dimensional inter-relationships of the major components of the human tracheobronchial tree. Surgery, Gynecology and Obstetrics, 105, 210.

Kensler, C. J. and Battista, S. P. (1966). Chemical and physical factors affecting mammalian ciliary activity. American Review of Respiratory Diseases, 93, (Suppl.), 93.

Lippmann, M. and Albert, R. E. (1969). The effect of particle size on the regional deposition of inhaled aerosols in the human respiratory tract. American Industrial Hygiene Association Journal, 30, 257.

,-- , and Peterson, H. T., Jr. (1971). The regional deposition of inhaled aerosols in man. In Inhaled Particles III, edited by W. H. Walton, Vol. 1, p. 105. Unwin, London.

Martin, D. and Jacobi, W. (1972). Diffusion deposition of small-sized particles in the bronchial tree. Health Physics, 23, 23.

Merendino, K. A. and Kiriluk, L. B. (1954). Human measurements involved in tracheobronchial resection and reconstruction procedures. Surgery, 35, 590.

Morrow, P. E., Gibb, F. R., and Gazioglu, K. M. (1967). A study of particulate clearance from the human lungs. American Review of Respiratory Diseases, 96, 1209.

Olson, D. E., Sudlow, M. F., Horsfield, K., and Filley, G. F. (1973). Convective patterns of flow during inspiration. Archives of Internal Medicine, 131, 51.

Owen, P. R. (1969). Turbulent flow and particle deposition in the trachea. In Circulatory and Respiratory Mass Transport: A Ciba Foundation Symposium, edited by G. E. W. Wolstenholme and J. Knight, p. 236. Churchill, London. Little, Brown, Boston.

Pedley, T. J., Schroter, R. C., and Sudlow, M. F. (1971). Flow and pressure drop in systems of repeatedly branching tubes. Journal of Fluid Mechanics, 46, 365.
Phalen, R. F., Yeh, H-C., and Raabe, O. G. (1975). The human tracheobronchial tree. Presented at American Industrial Hygiene Conference, 1-6 June, 1975, Minneapolis, Minnesota.

Proetz, A. W. (1951). Air currents in the upper respiratory tract and their clinical importance. Annals of Otology, Rhinology and Laryngology, 60, 439.

Santa Cruz, R., Landa, J., Hirsch, J. and Sackner, M. A. (1974). Tracheal mucous velocity in normal man and patients with obstructive lung disease; effects of $\vec{\omega}$ terbutaline. American Review of Respiratory Disease, 109, 458.

Schlesinger, R. B. (1975). The intrabronchial pattern of $\dot{\omega}$ particle deposition. Ph.D. Thesis, New York $\vec{\sigma}$ University.

- Cohen, V. R., and Lippmann, M. (1974). Studies of intrabronchial particle deposition using hollow bronchial casts. In Experimental Lung Cancer: Carcinogenesis and Bioassays, edited by E. Karbe and J. F. Park, p. 116. Springer, New York.

- and Lippmann, M. (1972). Particle deposition in casts of the human upper tracheobronchial tree. American Industrial Hygiene Association Journal, 33, 237.

Sekihara, T., Olson, D. E., and Filley, G. F. (1969). Airflow regimes and geometrical factors in the human airway. In Current Research in Chronic Respiratory Disease: Proceedings of the Eleventh Aspen Emphysema Conference, 1968, edited by R. S. Mitchell, p. 103. United States Department of Health, Education and Welfare, Washington DC.

Sisson, S. (1953). The Anatomy of the Domestic Animals, 4th edition, revised. Saunders, Philadelphia.

West, J. B. and Hugh-Jones, P. (1959). Patterns of gas $\overline{\bar{O}}$ flow in the upper bronchial tree. Journal of Applied Physiology, 14, 753.

Yeates, D. B., Aspin, N., Levison, H., Jones, M. T., and Bryan, A. C. (1975). Mucociliary tracheal transport rates in man. Journal of Applied Physiology, 39, 487.

Requests for reprints to: Dr. R. B. Schlesinger, Institute of Environmental Medicine, New York University Medical Center, 550 First Avenue, New York, NY 10016, USA. 